\title{
Efficacy of single-dose multidrug therapy for the treatment of single-lesion paucibacillary leprosy*
}

\author{
SINGLE-LESION MULTICENTRE TRIAL GROUP†
}

\begin{abstract}
Summary A multicentre double-blind controlled clinical trial was carried out to compare the efficacy of a combination of rifampicin $600 \mathrm{mg}$ plus ofloxacin $400 \mathrm{mg}$ plus minocycline $100 \mathrm{mg}(\mathrm{ROM})$ administered as single dose with that of the standard six-month WHO/MDT/PB regimen. The subjects included 1483 cases with one skin lesion who were previously untreated, were smear-negative, and had no evidence of peripheral nerve trunk involvement and they were randomly divided into study and control groups. The total duration of the study from the day of intake was 18 months, and 1381 patients completed study. Only 12 patients were categorized as treatment failure and no difference was observed between the two regimens. Occurrence of mild side-effects and leprosy reactions were minimal (less than 1\%) in both groups. This study showed that ROM is almost as effective as the standard WHO/MDT/PB in the treatment of single lesion PB leprosy.
\end{abstract}

\section{Introduction}

As leprosy control services are expanding in endemic countries, particularly through the implementation of WHO-recommended multidrug therapy (MDT), the number of new cases being detected has been steadily increasing and had reached a peak of about 650,000 new cases in 1992. Since then, the number of newly detected cases every year in the world is relatively constant, between 550,000 and 600,000 . About $85 \%$ of these are in Asia and it is found that the majority ( $50 \%$ or more) of these cases are being detected at the stage when the only visible sign of the disease is a single lesion (Gupte 1996, Peat et al. 1995, WHO 1996). Although it is well known that most of the single-lesion paucibacillary (PB) cases may heal spontaneously without any specific treatment (Ekambaram \& Sithambaram 1977), a significant proportion of such cases may develop more severe disease and be at risk of developing nerve damage. Taking into consideration the facts that the number of singlelesion cases form a large proportion of registered and new cases in countries undertaking active case finding, that a significant proportion of these cases are children, that compliance with the standard six-month MDT regimen difficult to maintain and that the six-month regimen may really be over-treatment for this group of patients, it was possible to consider these cases as a special group requiring a substantially reduced period of treatment. Therefore, the possibility of treating such single-lesion PB cases with three highly bactericidal drugs administered in a single dose was explored through a multicentre study.

* Reprinted, with permission, from Indian Journal of Leprosy, 1997; 69: 121-129.

† See p. 349 for individual members of the group. 
It had earlier been established that a single dose of rifampicin $600 \mathrm{mg}$ exerts a very strong bactericidal effect on Mycobacterium lepra (Ji et al. 1992, Levy et al. 1976). Addition of ofloxacin $400 \mathrm{mg}$ and minocycline $100 \mathrm{mg}$ has the potential to prevent the selection of rifampicin-resistant mutants, if any, in early single-lesion PB leprosy where the bacterial population is expected to be well below one million.

Rifampicin is by far the most effective bactericidal drug against M. leprae. Its activity is greater than that of any single or combination of the other antileprosy drugs. Rifampicin given as a monthly dose of $600 \mathrm{mg}$ is highly bactericidal against $M$. leprae and is almost as effective as daily rifampicin ( $\mathrm{Ji}$ et al. 1996). The toxicity of the drug is related to the dosage and the interval between doses. The standard dose of $600 \mathrm{mg}$ monthly in MDT regimens has proved to be relatively non-toxic, although occasional cases of renal failure, thrombocytopenia, influenza-like syndrome and hepatitis have been reported.

During the last decade, a large number of fluoroquinolones have been developed, and some, such as ciprofloxacin, are inactive against $M$. lepra; among those which are of most interest is ofloxacin. The results of clinical trials have indicated that its optimal dosage for the treatment of leprosy is $400 \mathrm{mg}$ daily. A single dose of ofloxacin displayed a modest bactericidal effect against $M$. leprae, and 22 doses killed $99.99 \%$ of the viable M. leprae (Grosset et al. 1990). Side-effects include nausea, diarrhoea and other gastrointestinal complaints, as well as a variety of central nervous system complaints including insomnia, headache, dizziness, nervousness and hallucinations. Most of these symptoms do not usually necessitate discontinuing ofloxacin treatment and serious problems are rare ( $\mathrm{Ji}$ et al. 1994).

Minocycline is the only member of the tetracycline group of antibiotics that has significant bactericidal activity against $M$. leprae. Its bactericidal activity against $M$. leprae is greater than that of clarithromycin, but much less than that of rifampicin. The standard dose is $100 \mathrm{mg}$ daily, which gives a peak serum level that exceeds the minimum inhibitory concentration of minocycline against $M$. leprae by a factor of 10-20 and has shown promising bactericidal activity in lepromatous patients (Gelber et al. 1992). Sideeffects include discolouration of teeth in infants and children, occasional pigmentation of the skin and mucous membrane, various gastrointestinal symptoms and central nervous system complaints, including dizziness and unsteadiness (Ji et al. 1993).

A multicentre double-blind controlled clinical trial was undertaken to compare the efficacy of a combination of rifampicin plus ofloxacin plus minocycline (ROM) administered as a single dose with that of the standard six-month WHO-PB regimen.

\section{Material and method}

\section{PATIENTS}

Based on a thorough clinical and bacteriological examination, all PB patients fulfilling the following criteria were included in the trial:

- having only one skin lesion (irrespective of size or location);

- previously untreated;

- skin-smear negative; and

- having no evidence of peripheral nerve trunk involvement.

The exclusion criteria were limited to the following:

- children below five years of age; 
Table 1. Distribution of patients included in the trial, by regimen, mean age, sex and mean clinical score at intake

\begin{tabular}{|c|c|c|c|c|c|c|}
\hline \multirow[b]{3}{*}{ No. of patients } & \multicolumn{4}{|c|}{ Regimen } & \multirow{2}{*}{\multicolumn{2}{|c|}{ Total }} \\
\hline & \multicolumn{2}{|c|}{ ROM } & \multicolumn{2}{|c|}{ WHO-PB } & & \\
\hline & 739 & $(49 \cdot 8 \%)$ & 744 & $(50 \cdot 2 \%)$ & 1483 & \\
\hline Mean age & $23 \cdot 6$ & $(\mathrm{SD} 15 \cdot 7)$ & $23 \cdot 4$ & $(\mathrm{SD} \mathrm{15.6)}$ & $23 \cdot 51$ & (SD 15.6) \\
\hline Females & 376 & $(50 \cdot 9 \%)$ & 353 & $(47 \cdot 4 \%)$ & 729 & $(49 \cdot 2 \%)$ \\
\hline Males & 363 & $(49 \cdot 1 \%)$ & 391 & $(52.6 \%)$ & 754 & $(50 \cdot 8 \%)$ \\
\hline Mean clinical score & $14 \cdot 3$ & $(\mathrm{SD} 0 \cdot 7)$ & $14 \cdot 3$ & $(\mathrm{SD} 0 \cdot 7)$ & $14 \cdot 31$ & $(\mathrm{SD} 0 \cdot 7)$ \\
\hline
\end{tabular}

- patients who were pregnant at the time of intake;

- patients known to be allergic to any of the proposed drugs or their derivatives, and

- those who were HIV positive, if tested, at the time of intake.

A total of 1483 patients were included in the trial, involving 754 males and 729 females. The mean age of the patients was $23 \cdot 5$ of years (SD 15.6). Characteristics of the patients by type of treatments are shown in Table I. No difference was observed at the intake between the two groups, indicating that the selection and randomization were acceptable.

Nine centres participated in the study, the number of patients per centre ranging from 103 to 400. The intake of patients started in September 1994 and ended by July 1995. The total duration of the study was 18 months (six months of treatment phase and 12 months of followup). Patients were examined every month for the first six months, then at the end of 12 and 18 months. Any patient not showing improvement at 18 months was put on the standard WHO/ MDT for PB.

\section{OUTCOME MEASURE}

The efficacy was measured in terms of clinical improvement, which was based on a scoring system involving five measurements:

- disappearance of the lesion;

- reduction in hypopigmentation/erythema;

- reduction in the degree of infiltration;

- reduction in the size of the lesion (using maximum/mean diameter, and/or actual mapping of the lesion); and

- improvement in sensation in the lesion (using some or all modalities, such as touch/ pain/thermal).

The maximal possible score at the intake was 15. During follow-up, the minimum possible score was zero.

\section{TREATMENT}

The study regimen (ROM): A single dose of rifampicin $600 \mathrm{mg}+$ ofloxacin $400 \mathrm{mg}+$ minocycline $100 \mathrm{mg}$.

(Children were given appropriately lower doses). 
The control regimen (WHO): WHO/MDT/PB (i.e. rifampicin $600 \mathrm{mg}$ monthly plus dapsone $100 \mathrm{mg}$ daily) for six months.

(Children were given appropriately lower doses).

All patients were treated for the full period of six months with appropriate drugs and placebo preparations, and followed up for 12 months thereafter. Patients were randomly allocated to the study or control regimens. This was done through a system of pre-coded treatment packs (incorporating identical-looking placebo preparations, as appropriate).

The administration of drugs was fully supervised (including placebos) in both regimens during monthly contacts. The six-month treatment was expected to be completed within nine months.

\section{EXAMINATION PROCEDURES}

At intake: Collection of information on patient identification, medical history and obtained informed consent; initial clinical examination and recording of the findings on standard forms (the characteristics of skin lesion, including the size, marked on the body outline chart); result of the initial skin-smear examination. Skin biopsy, histamine test, lepromin test, tests for HIV and detailed neurological examination was undertaken on an optional basis by centres which were capable of carrying them out in a satisfactory manner.

During treatment: Patients were seen and interviewed every month, either by the investigator or by an experienced paramedical worker, for symptoms and signs suggesting adverse reactions to drugs and reversal reaction, especially neuritis. Any suggestion of an unfavourable development found was reported to the Principal Investigator who examined the patient and took appropriate action. Drug intake was monitored through questionning of the patients and tablet counts during house calls.

At the end of treatment: At the end of six months' treatment, a formal clinical and skinsmear examination was performed. The degree of clinical improvement was assessed and recorded on standard forms.

After treatment: At the end of 12 and 18 months after the intake (or six months and 12 months after completion of treatment), a formal clinical and skin-smear examination was performed. The degree of clinical improvement was assessed and recorded on standard forms.

Statistical analysis: The multicentre trial had an overall trial coordinator to ensure that the trial protocol was followed uniformly in all the centres. Reporting forms were centralized, monitored and compiled at WHO, Geneva. Results were analyzed by Fisher's exact test. Differences were considered significant at the 95\% confidence level. Progress with the trial was reviewed periodically by the Steering Committee on chemotherapy of mycobacterial diseases (THEMYC), a component of the UNDP/World Bank/WHO Special Programme for Research and Training in Tropical Diseases (TDR).

\section{Results}

Out of the 1483 patients included in the trail, 1381 (93\%) were able to complete treatment and 18 months of follow-up after starting treatment. Information on the status at the end of 18 months was missing for eight patients and therefore they were not included in the analysis and 94 patients were removed from the trial for various reasons. 
Table 2. Response to treatment by regimen

\begin{tabular}{lrrrrrr}
\hline & \multicolumn{5}{c}{ Regimen } \\
\cline { 2 - 6 } Response & \multicolumn{2}{c}{ ROM } & \multicolumn{2}{c}{ WHO } & & Total \\
\hline No improvement or deterioration & 6 & $(0 \cdot 9 \%)$ & 6 & $(0 \cdot 9 \%)$ & 12 & $(0 \cdot 9 \%)$ \\
Clinical improvement & 691 & $(99 \cdot 1 \%)$ & 678 & $(99 \cdot 1 \%)$ & 1369 & $(99 \cdot 1 \%)$ \\
Total & 697 & & 684 & & 1381 & \\
\hline
\end{tabular}

$\mathrm{P}=1$.

PATIENTS DROPPED OUT FROM THE TRIAL

Out of 1483 patients, $94(6 \cdot 3 \%)$ dropped out of the trial (49 ROM and 54 WHO) for the following reasons: eight died $(0.5 \%), 10$ were due to adverse drug reactions, 56 due to migration, 19 due to refusal to continue treatment or follow-up, and one due to a mistake in drug administratiion. No difference was observed between the two regimens regarding drop outs or their causes $(\mathrm{P}=0 \cdot 16)$.

\section{RESPONSE TO TREATMENT}

Treatment failure: Treatment failure was defined as no change or increase of the clinical score at the end of the trial as compared to the score at the intake. As shown in Table II, 12 out of 1381 patients $(0.9 \%)$ fell in this category, i.e. they either did not improve (10 patients) or showed deterioration (two patients) at the 18-month examination. Comparison between the trial and control group showed no difference $(\mathrm{P}=1)$ with regard to treatment failure between the two regimens.

Analysis of the characteristics of the patients who failed to respond to treatment showed that six of them were males and six were females, and their mean age was 22 years. None of the patients had experienced drug side-effects, reversal reaction or neuritis. None of them had to be given steroids during the course of the treatment or the follow-up.

Marked improvement: Table III indicates that 753 out of 1381 patients $(54.5 \%$ of the patients or $36.3 \%$ of person-years) had shown a marked improvement at the end of the study. Marked improvement was defined as a difference of 13 between the initial score and the score at the end of 18 months. The cut-off point of 13 was selected on the basis of the distribution of the differences as shown in Table IV.

Table 3. Marked clinical improvement by regimen

\begin{tabular}{llcr}
\hline & \multicolumn{2}{c}{ Regimen } \\
\cline { 2 - 3 } Clinical improvement & ROM & WHO & Total \\
\hline No marked improvement & $336(48 \cdot 2 \%)$ & $292(42 \cdot 7 \%)$ & $628(45 \cdot 5 \%)$ \\
Marked improvement & $361(51 \cdot 8 \%)$ & $392(57 \cdot 3 \%)$ & $753(54 \cdot 5 \%)$ \\
Total & 697 & 684 & 1381 \\
\hline
\end{tabular}

Difference between two regimens statistically significant; $\mathrm{P}=0 \cdot 04$. 
Table III also shows that $51.8 \%$ of patients (or $34.5 \%$ of person years) treated with ROM and $57 \cdot 3 \%$ of patients (or $38.2 \%$ of person-years) treated with the standard six-month WHO/ PB regimen showed marked improvement. The small difference of $5 \cdot 5 \%(0 \cdot 1 \%-10 \cdot 9 \%)$ between the two regimens, however is statistically significant $(\mathrm{P}=0.04)$.

Complete cure: As seen in Table V, 701 out of 1381 patients (50.8\% of patients or $33.8 \%$ of person-years) were completely cured at the end of the study. Complete cure is defined as the total disappearance of the lesion and of the signs associated with it (clinical score of 0 ). Of those among the two regimens $46.9 \%$ of patients (or $31.2 \%$ of person-years) treated with ROM and $54.7 \%$ of patients (or $36.3 \%$ of person-years) treated with the standard six-month WHO/PB regimen were cured. The difference of $7 \cdot 8 \%(2 \cdot 4 \%-13 \cdot 2 \%)$ between the two regimens is statistically significant $(P=0.004)$.

\section{SIDE-EFFECTS}

During the course of treatment, 12 out of 1483 patients $(0.8 \%)$ had symptoms which were related to possible adverse reaction to drugs. Ten of these were adverse reactions, leading to the exclusion of the patients from the trial, and for two patients the treatment was continued. Five out of the 12 patients had shown gastrointestinal problems (three ROM and two WHO regimen) and the other seven had allergies (one ROM and six WHO regimen). All these patients recovered fully after appropriate treatment. The occurrence of adverse reactions was not significantly different between the two groups $(P=0 \cdot 10)$.

Table 4. Evolution of the clinical score between intake and 18 months by regimen

\begin{tabular}{|c|c|c|c|c|c|c|}
\hline \multirow{2}{*}{$\begin{array}{l}\text { Clinical score difference* } \\
\text { (Score at intake-score } \\
\text { at } 18 \text { months }\end{array}$} & \multicolumn{2}{|c|}{ ROM regimen } & \multicolumn{2}{|c|}{ WHO regimen } & \multicolumn{2}{|c|}{ Total } \\
\hline & $\begin{array}{l}\text { Number of } \\
\text { patients }\end{array}$ & $\underset{\%}{\text { Cumulative }}$ & $\begin{array}{l}\text { Number of } \\
\text { patients }\end{array}$ & $\underset{\%}{\text { Cumulative }}$ & $\begin{array}{l}\text { Number of } \\
\text { patients }\end{array}$ & $\begin{array}{c}\text { Cumulative } \\
\%\end{array}$ \\
\hline-2 & $0 \cdot 1$ & $0 \cdot 1$ & 0 & 0 & 1 & $0 \cdot 1$ \\
\hline-1 & 1 & $0 \cdot 3$ & 0 & 0 & 1 & $0 \cdot 1$ \\
\hline 0 & 4 & $0 \cdot 9$ & 6 & 0.9 & 10 & $0 \cdot 9$ \\
\hline 1 & 7 & $1 \cdot 9$ & 3 & $1 \cdot 3$ & 10 & $1 \cdot 6$ \\
\hline 2 & 4 & $2 \cdot 4$ & 3 & $1 \cdot 8$ & 7 & $2 \cdot 1$ \\
\hline 3 & 11 & $4 \cdot 0$ & 8 & $2 \cdot 9$ & 19 & $3 \cdot 5$ \\
\hline 4 & 26 & $7 \cdot 7$ & 13 & $4 \cdot 8$ & 39 & $6 \cdot 3$ \\
\hline 5 & 19 & $10 \cdot 5$ & 16 & $7 \cdot 2$ & 35 & $8 \cdot 8$ \\
\hline 6 & 35 & $15 \cdot 5$ & 38 & $12 \cdot 7$ & 73 & $14 \cdot 1$ \\
\hline 7 & 41 & $21 \cdot 4$ & 33 & $17 \cdot 5$ & 74 & $19 \cdot 5$ \\
\hline 8 & 43 & $27 \cdot 5$ & 36 & $22 \cdot 8$ & 79 & $25 \cdot 2$ \\
\hline 9 & 48 & $34 \cdot 4$ & 32 & $27 \cdot 5$ & 80 & $31 \cdot 0$ \\
\hline 10 & 38 & $39 \cdot 9$ & 42 & $33 \cdot 6$ & 80 & $36 \cdot 8$ \\
\hline 11 & 38 & $45 \cdot 3$ & 26 & $37 \cdot 4$ & 64 & $41 \cdot 4$ \\
\hline 12 & 20 & $48 \cdot 2$ & 36 & $42 \cdot 7$ & 56 & $45 \cdot 5$ \\
\hline 13 & 72 & $58 \cdot 5$ & 68 & $52 \cdot 6$ & 140 & $55 \cdot 6$ \\
\hline 14 & 150 & $80 \cdot 1$ & 174 & $78 \cdot 1$ & 324 & $79 \cdot 1$ \\
\hline 15 & 139 & $100 \cdot 0$ & 150 & $100 \cdot 0$ & 289 & $100 \cdot 0$ \\
\hline Total & 697 & $100 \cdot 0$ & 684 & $100 \cdot 0$ & 1384 & $100 \cdot 0$ \\
\hline
\end{tabular}

\footnotetext{
* A negative difference indicates deterioration, a positive one improvement.
} 
Table 5. Number of patients completely cured by regimen

\begin{tabular}{llrr}
\hline & \multicolumn{3}{c}{ Regimen } \\
\cline { 2 - 4 } Response & ROM & WHO & Total \\
\hline Not completely cured & $370(53 \cdot 1 \%)$ & $310(45 \cdot 3 \%)$ & $680(49 \cdot 2 \%)$ \\
Completely cured & $327(46 \cdot 9 \%)$ & $374(54 \cdot 7 \%)$ & $701(50 \cdot 8 \%)$ \\
Total & 697 & 684 & 1381 \\
\hline
\end{tabular}

Difference between regimens statistically significant; $\mathrm{P}=0 \cdot 04$.

\section{LEPROSY REACTIONS DURING THE STUDY}

Ten cases developed mild reversal reactions during or after treatment. On average, reactions had occurred within 42 weeks of starting the treatment. Seven cases belonged to ROM and three to WHO regimen $(\mathrm{P}=0 \cdot 22)$. None of these reactions required hospitalization and all recovered fully after appropriate treatment. Among the 10 reactions, four patients had developed neuritis (three with ROM regimen, and with WHO regimen, $\mathrm{P}=0 \cdot 37$ ).

\section{Discussion}

The results of this trial indicate that a single dose of rifampicin $600 \mathrm{mg}$, ofloxacin $400 \mathrm{mg}$ and minocycline $100 \mathrm{mg}$ is almost as effective as the standard WHO/PB/MDT in the treatment of single lesion PB leprosy. Less than $1 \%$ of the patients did not improve at the end of 18 months in both groups. Occurrence of mild side-effects and leprosy reactions were minimal (less than $1 \%$ ), indicating that the ROM regimen can be as safely administered under field conditions as WHO/MDT.

Even if it was not possible to establish the bacterial cure of the patients, there is enough direct evidence from the trial to show that the ROM regimen is able to perform as well as the $\mathrm{WHO} / \mathrm{PB} / \mathrm{MDT}$ regimen in killing the relatively small population of $M$. leprae that singlelesion PB patients harbour.

Total disappearance of the lesion in $50 \%$ of the patients within 18 months of starting treatment can generally be considered as satisfactory. The marginal but statistically significant difference observed between the two regimens indicates that standard WHO/ MDT is slightly more effective in the complete healing of skin lesion. This is possibly related more to non-antibacterial effects than to antibacterial effects of the drugs used. Assuming that the annual cure rates remain constant, it is expected that nearly all patients will be cured, although the standard WHO/PB/MDT is likely to do it slightly faster than ROM.

While the selection of patients and the multicentre randomized nature of the study helped in minimizing the biases, it was not possible to objectively confirm the specificity of all the diagnoses. In addition, the fact that a significant proportion of single-lesion patients have a tendency for self-healing could have had a confounding effect with regard to results obtained. For evident ethical reasons, it was not possible to have a control group without treatment and therefore the self-healing rate for this group of patients will not be known. It is believed that all the factors which could have introduced some bias were equally distributed and that the sample size was large enough to incorporate a significant proportion of patients who would 
not have been cured without treatment. It should be recognized, however, that a significant number of single-lesion PB patients are being diagnosed in leprosy programmes of endemic countries and that they cannot be left without treatment irrespective of their tendency for selfhealing. A single dose of ROM seems to be an acceptable and cost-effective alternative having many operational advantages. From the patient's point of view, a single-dose treatment would probably be the treatment of choice as it would definitely help in completing treatment quickly and in suppressing the stigma attached to leprosy. However, there may be several potential operational disadvantages, such as possible overdiagnosis, difficulties in handling powerful antibiotics under field conditions, difficulties in monitoring drug utilization and patients' registration, and these should not be overlooked.

\section{Conclusion}

This double-blind clinical trial has demonstrated that a single dose of rifampicin, ofloxacin and minocycline (ROM) is almost as effective as the standard six-months WHO/PB/MDT regimen in the treatment of single-lesion PB leprosy.

\section{Acknowledgment}

This study received financial support from the UNDP/World Bank/WHO Special Programme for Research and Training in Tropical Diseases (TDR), and was coordinated by the Action Programme for the Elimination of Leprosy, WHO, Geneva.

\section{References}

${ }^{1}$ Ekambaram V, Sithambaram M. Self-healing in non-lepromatous leprosy in the area of ELEP Leprosy Control Project, Dharmapuri (Tamil Nadu). Indian J Lepr, 1977; 49: 387-392.

2 Gelber RH, Fukuda K, Byrd S et al.. A clinical trial of minocycline in lepromatous leprosy. Br Med J, 1992; 304: 91-92.

${ }^{3}$ Grosset JH, Ji B, Guelpa-Lauras CC et al.. Clinical trial of pefloxacin and ofloxacin in the treatment of lepromatous leprosy. Int J Lepr, 1990; 58: 281-295.

4 Gupte MD. Presidential address at the XIX Biennial Conference of Indian Association of Leprologists (15-17 December 1995, Pune). Indian J Lepr, 1996; 68: 211-213.

5 Ji B, Perani EG, Petinon C, Grosset JH. Bactericidal activities of single or multiple doses of various combinations of new antileprosy drugs and/or rifampin against $M$ leprae in mice. Int J Lepr, 1992; 60: 556-561.

6 Ji B, Jamet P, Perani EG et al. Powerful bactericidal activities of clarithromycin and minocycline against Mycobacterium leprae in lepromatous leprosy. J Infect Dis, 1993; 168: 188-190.

7 Ji B, Perani EG, Petinon C et al.. Clinical trial of ofloxacin alone and in combination with dapsone plus clofazimine for treatment of lepromatous leprosy. Antimicrob Agents Chemother, 1994; 38: 662-667.

${ }^{8} \mathrm{Ji} \mathrm{B}$, Perani EG, Petinon C, Grosset JH. Bactericidal activities of combinations of new drugs against Mycobacterium leprae in nude mice. Antimicrob Agents Chemother 1996; 40: 393-399.

9 Levy L, Shepard CC, Fasal P. The bactericidal effect of rifampicin on M leprae in man (a) single doses of 600,900 and $1200 \mathrm{mg}$; and (b) daily doses of $300 \mathrm{mg}$. Int J Lepr, 1976; 44: 183-187.

10 Peat M, Brolin L, Ganapati R et al.. An evaluation of the contribution of the Swedish International Development Authority (SIDA) to leprosy control in India based on the implementation of multiple drug therapy (MDT) 19811993. Indian J Lepr, 1995; 67: 447-465.

11 WHO 1996. Progress towards the elimination of leprosy as a public health problem. WHO Weekly Epidemiological Record, 1996, 1996; 71(18): 149-156. 
Single-lesion Multicentre Trial Group consisted of:

Dr G Rajan Babu, Epidemiologist on Special Duty, The Leprosy Mission India, New Delhi, India. Dr VK Edward, Physician and Superintendent, Richardson Leprosy Hospital, The Leprosy Mission India, Miraj, India; Dr MD Gupte, Officer-in-charge, CJIL Field Unit, Madras, Indica. Dr P Krishnamurthy, Secretary, Damen Foundation India Trust, Madras, India; Dr Inder Parkash, Assistant Director, Epidemiology, Central Leprosy Teaching and Research Institute, Chengalpattu, India; Dr V Rajendran, Hemerijckx Government Leprosy Centre, Polambakkam, India; Dr C Revankar, Deputy Director, Bombay Leprosy Project, Bombay, India. Dr SB Taranekar, Director, Regional Leprosy Training and Research Institute, Raipur, India. Dr P Vijayakumaran, Associate Epidemiologist, Schieffelin Leprosy Research and Training Centre, Karigifri, India Trial co-ordinator. Dr V Pannikar, WHO, Geneva. 